\title{
CASA DA MULHER CATARINA - SEMINÁRIOS DE CONTROVÉRSIAS
}

\author{
Lilly Ana Aichinger ${ }^{1}$ \\ Clair Castilhos Coelho ${ }^{2}$ \\ Jane Maria de Souza Philippi ${ }^{3}$
}

\section{RESUMO}

O projeto de extensão Casa da Mulher Catarina, do Departamento de Saúde Pública da UFSC realizou uma série de seminários intitulados Relações de Poder nas Relações de Gênero. Os temas abordados foram polêmicos, como desigualdade, saúde da mulher, participação política, direitos sexuais e reprodutivos, e raça/etnia. Foi uma experiência gratificante para o grupo da Casa da Mulher Catarina, onde as palestrantes acadêmicas tiveram a oportunidade de repassar suas experiências e conhecimentos aprendidos e exercer a cidadania.

Palavras-chave: Seminários. Direitos e saúde da mulher. Relações de gênero.

\section{WOMEN'S HOUSE CATARINA - SEMINARS CONTROVE}

\begin{abstract}
The extension project of Women's House Catarina, Department of Public Health UFSC held a series of seminars entitled Relations of Power in Gender Relations. The topics were controversial, such as inequality, women's health, political participation, sexual and reproductive rights, and race / ethnicity. It was a rewarding experience for the group Women's House Catarina, where the academic lecturers had the opportunity to pass on their experiences and knowledge learned and exercising citizenship.
\end{abstract}

Keywords: Seminars. Women's rights and health. Gender relations.

\footnotetext{
${ }^{1}$ Acadêmica do Curso de Medicina da UFSC - lillyaichinger@yahoo.com.br

${ }^{2}$ Professora do Departamento de Saúde Pública da UFSC - Clair.castilhos@gmail.com

${ }^{3}$ Professora do Departamento de Saúde Pública da UFSC - janemsp@gmail.com
} 


\section{INTRODUÇÃO}

A Casa da Mulher Catarina é um projeto de extensão do Departamento de Saúde Pública da UFSC desde 1989. É o mais antigo grupo feminista de Santa Catarina, dedicando-se a saúde da mulher, participação política, direitos sexuais e reprodutivos, e raça/etnia. É reconhecida internacionalmente como defensora dos direitos das mulheres e visa refletir e agir sobre a mulher e sua condição. Dentro desse projeto, realizou em 2008 um conjunto de atividades intituladas "Seminários de Controvérsias", cujos temas foram sobre a saúde da mulher, sua participação na política, e seus direitos sexuais, direitos reprodutivos e raça/etnia. São de fundamental importância que a Casa da Mulher Catarina promova eventos sobre a mulher e sua condição, para trazer discussões atuais e promover a educação em saúde dentro do espaço universitário, e também fora deste espaço, para a comunidade.

Os objetivos do projeto foram a realização de seminários destinados a debater a condição da mulher nos âmbitos da saúde, política e educação, na perspectiva de gênero e na reivindicação de políticas públicas fortalecendo a condição da feminina, a articulação com outras organizações que também abordem os temas propostos nos seminários, a interação entre as estudantes que participam das atividades da Casa da Mulher Catarina e a comunidade, a promoção de educação em saúde da mulher, e a discussão sobre a condição da mulher, aos estudantes de uma maneira geral e à comunidade.

\section{MATERIAL E MÉTODOS}

Os Seminários de Controvérsias "Relações de Poder nas Relações de Gênero" da Casa da Mulher Catarina foram divididos em três etapas: $1^{\circ}$ Seminário - Gênero e Igualdade, $2^{\circ}$ Seminário - Meu corpo me pertence, e $3^{\circ}$ Seminário - As controvérsias do aborto. Tiveram a duração de 4 horas cada, sendo três horas de palestras e mais uma hora para debates e discussões.

A estrutura dos seminários foi composta de uma abertura com apresentação inicial da Casa da Mulher Catarina; palestras sobre os temas específicos de cada seminário; debate aberto com os participantes e as palestrantes e distribuição de material explicativo.

Foram confeccionados cartazes de propaganda para divulgação do evento na Universidade e em órgãos públicos, assim como folhetos explicativos para distribuição nos eventos. 
O público alvo foram as participantes da Casa da Mulher Catarina, os estudantes, professores e funcionários da Universidade, as participantes de entidades relacionadas aos direitos da mulher, e pessoas interessadas nos temas abordados.

\section{RESULTADOS E ANÁLISE}

O $1^{\circ}$ Seminário, intitulado "Gênero e Igualdade" aconteceu no Auditório do Centro de Ciências da Saúde/UFSC, em 03/06/2008, às 19 horas, com quatro palestras: "Gênero e desigualdade no cotidiano das mulheres”, “A Saúde das Presidiárias de Santa Catarina”, “A visão de docentes do ensino em saúde sobre o aborto", e "Experiências com populações ribeirinhas na Amazônia".

O $2^{\circ}$ Seminário, intitulado "Meu corpo me pertence", aconteceu no Plenarinho da Assembléia Legislativa do Estado de Santa Catarina, em 01/07/2008, às 19 horas, com três palestras: "Mortalidade Materna", "Direitos Sexuais e Direitos Reprodutivos", e "Mulheres que sofrem violência".

O $3^{\circ}$ Seminário, intitulado "As controvérsias do aborto", aconteceu na Sala 926 do CCS/UFSC, em 18/09/2008, às 14 horas, com o filme "Aborto: um tema em debate" produzido pela organização Católicas pelo Direito de Decidir.

Após os seminários aconteceram os debates e discussões sobre os temas.

\section{CONSIDERAÇÕES FINAIS}

O conteúdo dos seminários foi de ótimo nível devido à experiência prática das palestrantes sobre os assuntos, professoras do Departamento de Saúde Pública, voluntárias da Casa da Mulher Catarina, bolsista do Proextensão e acadêmicas voluntárias, e principalmente por abordar temas polêmicos. As acadêmicas tiveram a oportunidade de discutir sobre os conhecimentos aprendidos, exercendo a cidadania. No entanto, como ponto negativo destacou-se a pouca audiência nos seminários.

Foi uma experiência gratificante para o grupo da Casa da Mulher Catarina, devendo ser repetida, mas para grupos específicos de pessoas, como associações de moradoras de bairros, sendo levado até onde as pessoas estão e necessitam de informações.

Investir nas mulheres significa promover a igualdade com justiça social, valorizar e promover a sua participação por uma cidadania plena, por relações de gênero equitativas e solidárias. 
Os Seminários contribuíram para a interação da bolsista e das acadêmicas voluntárias da Casa da Mulher Catarina com outros estudantes e com a comunidade, pois além de transmitirem seus conhecimentos através das palestras, debateram e discutiram a promoção da saúde sobre temas atuais e controversos.

\section{AGRADECIMENTOS}

Agradecemos o apoio do PROEXTENSÃO/UFSC.

\section{REFERÊNCIAS}

BARROS, José Augusto Cabral de. A medicalização da Mulher no Brasil. In: WOLFFERS, Ivan e JANSEN, Anita (Org.). O Marketing da fertilidade: menstruação, aborto e indústria farmacêutica. São Paulo: Ed. Hucitec, 1991.

BEAUVOIR, Simone de. O segundo sexo - 1. Fatos e Mitos. Tradução de Sérgio Milliet, $3^{\mathrm{a}}$ Edição, São Paulo: Difel, 1968.

BRASIL. MINISTÉRIO DA SAÚDE. Secretaria de Atenção à Saúde. Departamento de Ações Programáticas estratégicas. Estudo da mortalidade de mulheres de 10 a 49 anos, com ênfase na mortalidade materna: relatório final. Brasília: Ministério da Saúde, 2006.

FOUCAULT, Michel. História da Sexualidade I: a vontade de saber. Rio de Janeiro: Graal, 1985.

PEDRO, Joana Maria. Práticas proibidas: práticas costumeiras de aborto e infanticídio no século XX. Florianópolis: Ed. Cidade Futura, 2003.

REDE FEMINISTA DE SAÚDE. A presença da mulher no controle social das políticas de saúde. Belo Horizonte: Mazza, 2003. 